Further Section

Cerebrovasc Dis 1991;1:359-360

Announcement

FINAL ANNOUNCEMENT

AND

RULES

FOR SUBMITTING

ABSTRACTS

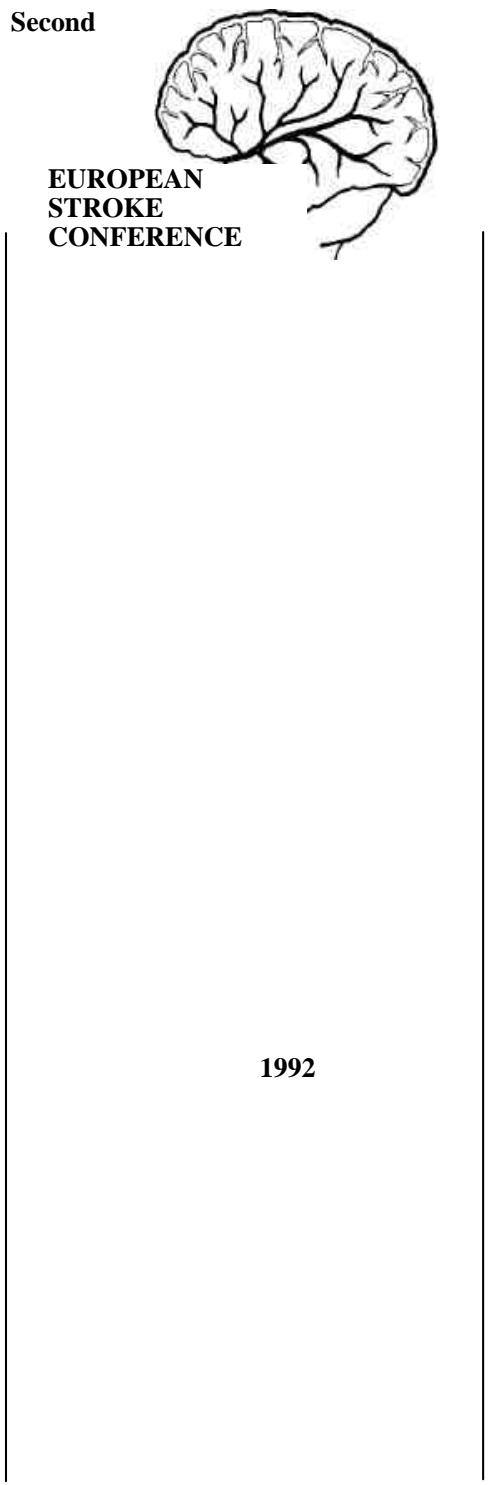


JUNE 25-27

LAUSANNE

SWITZERLAND 


\section{GENERAL INFORMATION}

- Deadline Date: Abstract must be received at Mannheim, FRG, no later than January 15, 1992.

- Abstract selection are based on scientific merit and are allocated to side or poster presentation. Guidelines for presentation will be provided if the abstract is selected.

- The abstract (an original plus eight copies) must be submitted on the enclosed form. If selected, it will be photographed and printed in the June 1992 issue of Cerebrovascular Diseases.

If the abstract is accepted for publication, the author must present the paper at the meeting. Resubmission of an abstract to make corrections or changes is not possible.

\section{MAILING INSTRUCTIONS}

1. Send the abstract form (original and eight copies), title card, and abstract notification card to

M. Hennerici, Mannheim.

2. Do not fold abstract form.

3. Use cardboard backing to prevent damage to abstract during mailing.

4. Send foreign abstract by foreign air mail.

5. Abstract must be received at Mannheim, FRG, not later than January $15,1992$.

Mail to:

Dr. Michael Hennerici Neurologische Klinik Universitdt zu Heidelberg Theodor-Kutzer-Ufer D-6800 Mannheim Federal Republic of Germany 


\section{PREPARATION OF ABSTRACTS}

\section{Read carefully before typing abstract. Abstracts not strictly adhering to these requirements will be disqualified.}

Organize abstract as follows:

1. To assure legibility, a minimum of 12-pitch type or the equivalent ( 12 characters per inch $=12$ characters per $25 \mathrm{~mm}$ ) is required. The entire abstracts must fit within space provided on abstract form.

2. Use a short, specific title indicating the nature of the investigation. Do not use abbreviations in the title.

3. List first name, middle initial, and last name of the author, omitting degrees and titles. Conclude with name of institution, city, and country of senior author.

4. Describe briefly the objectives of the study unless they are contained in the title.

5. Include a brief statement of methods if pertinent.

6. State findings in sufficient detail to support conclusions.

7. A statement of conclusions should be included.

8. Formulas should be avoided. Special symbols and graphs should be drawn in black ink. Use generic drug names.

9. Standard abbreviations may be used without definition. Abbreviations not defined must be placed in parantheses after the full word at first mention in body of abstract: such abbreviations should be kept to a minimum.

10. Do not include proprietary names of drugs and references.

11 Abstracts without statements about the number of experimental subjects and appropriate statistical analysis will be given a low priority. 


\section{Announcement}

Deadline Date:

Abstracts must be received no later than January 15, 1992 Send original and 8 copiesP " 


\section{Abstract Form}

Name of corresponding author:

Last Name

First Name

M.I.

Deportment

Institution

Street Address

Postal Code

Oty

Country
Fax or Tele

Telephone

$$
\text { or }
$$




\section{Second \\ European Stroke \\ Conference}

June 25-27, 1992 lausanne, Switzerland

For review and grading, assign my abstract to the areas checked below:
D Blood Flow/
Title
Clinical
Authors
D Hematology/
Text
D Diagnosis
$\square$ Ultrasound
D Epidemiology
D Experimental
a Metabolism
a Pathology/
D Physical Therapy and
Rehabilitation
D Surgery
D Vascular Physiology
D Interventional
Aspects
D Therapy

Type title, authors and abstract here - stay strictly within border!

Author's Signature 